\title{
Professor MNT Fonseka, FRCS (London), FRCS (Edin), FRCOG (Great Britain)
}

My cousin, Merrennage Neil Thomas Foneka (Neil), born 19 July 1940, died of an incurable and progressive brain disease on 15 May 2005.

Neil and I grew up together as schoolboys at his parents' friendly home in Kent Road, Dematagoda, along with his four siblings. Neil shared many interests with me, such as soft-ball cricket, watching adventure movies (e.g. Lone Ranger's exploits, the Fu Manchu series, the Captain Marvel series etc), reading Bernand Shaw and Oscar Wilde, and spreading as much mischief as possible in the neighbourhood. For the last activity we were nearly always appropriately disciplined by Neil's mother, but alas, to no avail. As for soft-ball cricket, Neil was an outstanding allrounder, and a valuable resource at the customary postmatch disagreements between the teams, because of his height, strength and courage. Dematagoda and Maradana were tough localities then as now.

His early schooling was at St. Matthew's College, Dematagoda, but he soon entered Ananda College, where he excelled in studies, winning along the way several prizes, as well as in sports (under-16 cricket team; under16 and under-19 soccer, high jump, long jump and triple jump for Gemunu House).

At the Faculty of Medicine of the University of Colombo he obtained Second Class Honours in all examinations, winning distinctions in Microbioogy, Pathology and Obstetrics and Gynaecology, and the Loos gold medal for Pathology.

His special postgraduate surgical experience overseas included colon and rectal surgery at St. Marks in London, urological surgery at the Institute of Urology in London, and in prosthetics and orthotics at the Glasgow University. He held appointments as Surgical Registrar at St. Bartholomews in London, and Senior Registrar in Surgery at Charing Cross Hospital in London, and at King Edward VII Hospital, Windsor. In 1976, he was appointed Surgeon to the Prosthetic and Vascular Centre at Selly Oak Hospital in Birmingham, and in 1978, Surgeon-incharge at the Prosthetic and Vascular Centre at Brighton Hospital. During his sabbatical years he served as a Consultant Surgeon in Saudi Arabia's King Fahd Hospital, and the Armed Forces Hospital in Oman.

In September 1980, he returned to Sri Lanka to take up appointment as the founder Professor in Surgery in the fledgeling Faculty of Medicine at the University of Ruhuna, a post he held with distinction. He participated in many activities of the Faculty, both academic and extracurricular, such as Buddhist religious activities and student and staff welfare. He was a member of the Senate and Council of the University, and became Dean of the

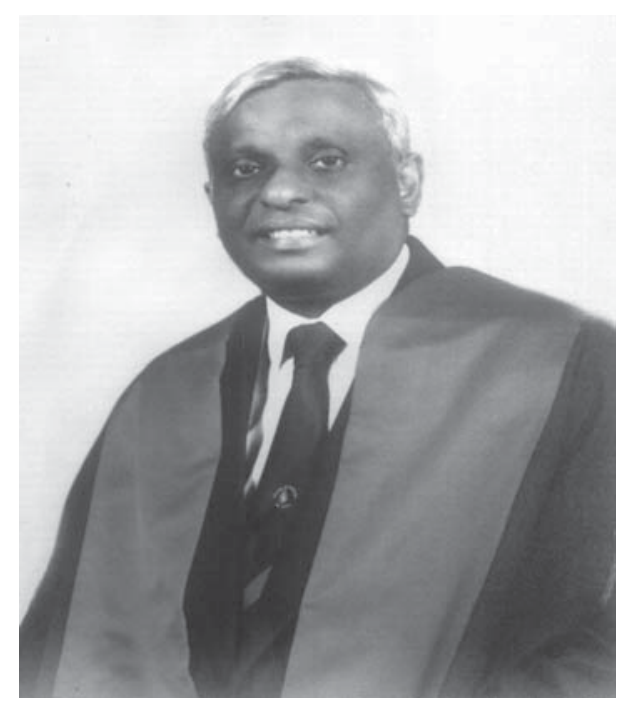

Faculty in 1988 - 89, the horrifying years of JVP terrorist mayhem. He was also a member of the Board of Study in Surgery, and Board of Management, as well as an Examiner for many years in surgery at the Postgraduate Institute of Medicine, Sri Lanka.

As a teacher in the Faculty of Medicine he was firm but kind, and didactic in style of teaching. He was, by all accounts, a fair examiner, although his mere presence was often dominant. He tended to be a firm disciplinarian, and did not brook trouble-makers either in the Faculty of Medicine or in the Teaching Hospital.

He was founder President and later Patron of the Ruhuna University Medical Students Alumni Association, founder of the Jaipur Foot Project (Galle Branch), President and later Patron of the Cancer Society (Galle Branch), and President of the Galle Medical Association (1985). He gave voluntary service to the Sri Lanka Army in Palaly, and was an All-Island Justice of the Peace.

He enjoyed a popular private practice as a general surgeon, trained many postgraduates in the theory and techniques of surgery, and maintained a genuine long term interest in his trainees. There are hardly any aspects of community life in the Galle District that his forceful personality did not touch. I was privileged to know Neil as his "elder brother", a colleague, and a friend. He is survived by his wife Pushpa, Professor of Community Medicine at the University of Ruhuna, who looked after him with professional expertise and devotion during his long and disabling illness.

Colvin Goonaratna, Editor, Ceylon Medical Journal; e-mail: <colvin_goonaratna@yahoo.com>. 